\title{
Diurnal variation pattern of Antipsychotic Drug, Benzodiazepine Dosing in Terminal cancer patients
}

\author{
Young Mi Seol, Hyo Jeong Kim, Young Jin Choi
}

Department of Hematology/Oncology, Pusan National University Hospital Medical Research Institute, Busan, Korea

\section{Background}

Delirium is highly prevalent in those with serious or advanced medical illnesses. It is associated with many adverse consequences, including significant patient, family, and health care provider distress. Anecdotal observation suggests that cancer patients in palliative care units receive higher doses of psychoactive medications during evening shifts than day and night shifts.

To determine the dosing patterns and total doses of psychoactive medications according to nursing shift in a cohort of cancer patients in a palliative care unit.

\section{Material and Methods}

\section{Patients}

Retrospective review of the charts of 256 consecutive patients with advanced cancer who were admitted to palliative care cancer center between January 1, 2013 and December 31, 2017.

(1) a diagnosis of delirium based on clinical diagnosis by a palliative medicine specialist or a score $\geq 7 / 30$ on the Memorial Delirium Assessment Scale (MDAS)

(2)treatment with first generation antipsychotics (haloperidol, risperidone, olanzapine, quetiapine) and/or benzodiazepine for delirium.

2. Study procedure-Collect the following information

- Patients information

demographics, cancer diagnosis, duration of palliative cancer center stay, source of admission, discharge information, delirium characteristics, response to neuroleptics, and the haloperidol equivalent daily dose.

- Medication

time, dose, and route of administration of all medications, All routes of drug administration were included in the dosing calculation. The medication data were then grouped to represent time of day by nursing shift: day (7 AM to 4 PM), evening (4 PM to midnight), and night (midnight to $7 \mathrm{AM}$ ).

\begin{tabular}{|c|c|c|c|}
\hline \multicolumn{4}{|c|}{ Results } \\
\hline \multicolumn{4}{|c|}{ Table 1. Patient characteristics } \\
\hline Characteristics & $\begin{array}{l}\text { Entire } \\
\text { cohort } \\
(n=256)\end{array}$ & $\begin{array}{l}\text { First generation } \\
\text { antipsychotics } \\
\text { only } \\
(n=194,76 \%)\end{array}$ & $\begin{array}{l}\text { Benzodiazepine } \\
(n=62,24 \%)\end{array}$ \\
\hline Median age (95\% CI, yr) & $63(61-66)$ & $62(60-64)$ & $65(62-67)$ \\
\hline Gender (female) & $104(41 \%)$ & $85(44 \%)$ & $19(31 \%)$ \\
\hline \multicolumn{4}{|l|}{ ECOG } \\
\hline 2 & 15 & 15 & 0 \\
\hline 3 & 157 & 143 & 14 \\
\hline 4 & 84 & 36 & 48 \\
\hline \multicolumn{4}{|l|}{ Cancer } \\
\hline Gastrointestinal & $89(35 \%)$ & 64 & 25 \\
\hline Lung & $38(15)$ & 32 & 6 \\
\hline Breast & $39(15)$ & 34 & 5 \\
\hline Gynecologic & $24(9)$ & 20 & 4 \\
\hline Genitourinary & $17(7)$ & 9 & 8 \\
\hline Sarcoma & $8(3)$ & 5 & 3 \\
\hline Head and neck & $21(8)$ & 14 & 7 \\
\hline Other & $20(8)$ & 15 & 5 \\
\hline $\begin{array}{l}\text { Median PCU stay (IQR, } \\
\text { day) }\end{array}$ & $10(6-14)$ & $14(7-21)$ & $6(3-7)$ \\
\hline $\begin{array}{l}\text { Median MDAS at } \\
\text { admission (IQR, day) }\end{array}$ & $11(8-18)$ & $19(8-24)$ & $13(8-26)$ \\
\hline \multicolumn{4}{|l|}{$\begin{array}{l}\text { Median symptom scale } \\
\text { (IQR) }\end{array}$} \\
\hline Pain & $5(3-8)$ & $5(3-8)$ & $6(3-8)$ \\
\hline Nausea & $3(0-5)$ & $3(0-5)$ & $3(1-5)$ \\
\hline Appetite & $5(3-8)$ & $5(3-8)$ & $6(5-8)$ \\
\hline Wellbeing & $6(3-8)$ & $5.5(3-8)$ & $6(5-8)$ \\
\hline Sleep & $4.5(2-6)$ & $4(2-6)$ & $5(3-8)$ \\
\hline DNR at admission & $243(95)$ & 183(94) & $60(97)$ \\
\hline Inpatient mortality & $177(69)$ & $126(65)$ & $51(82)$ \\
\hline
\end{tabular}

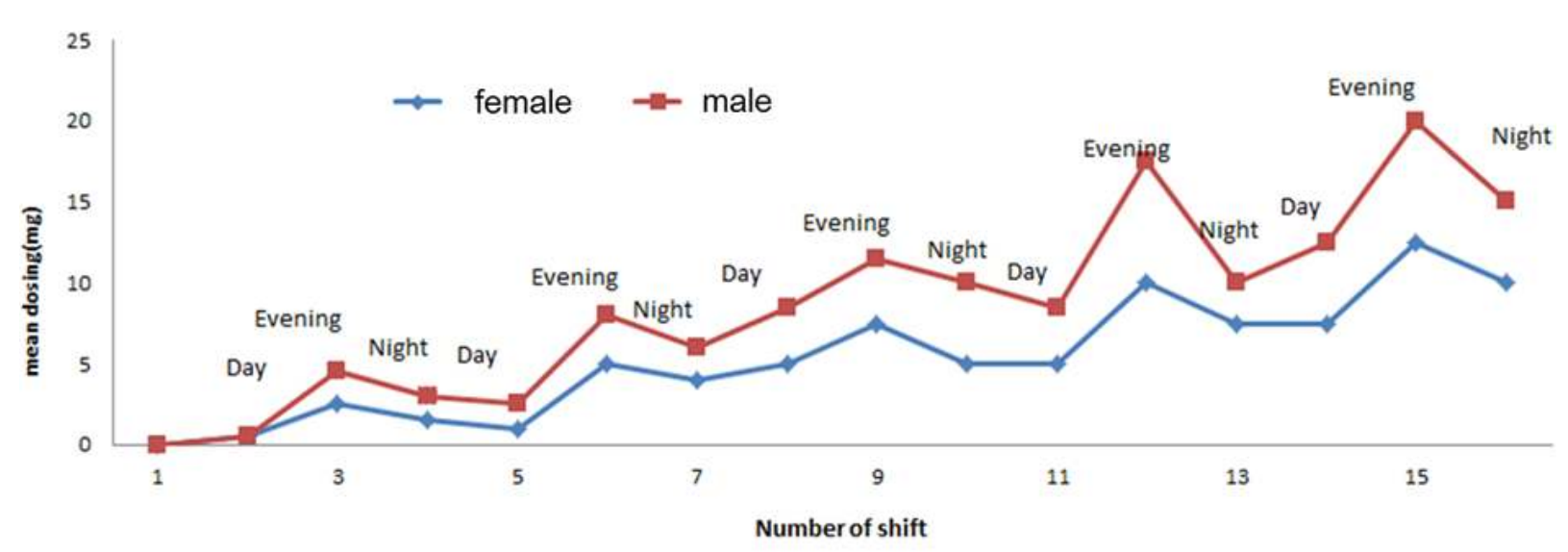

Figure 1 Mean doses of first generation psychoactive drug (Haloperidol) by shift number

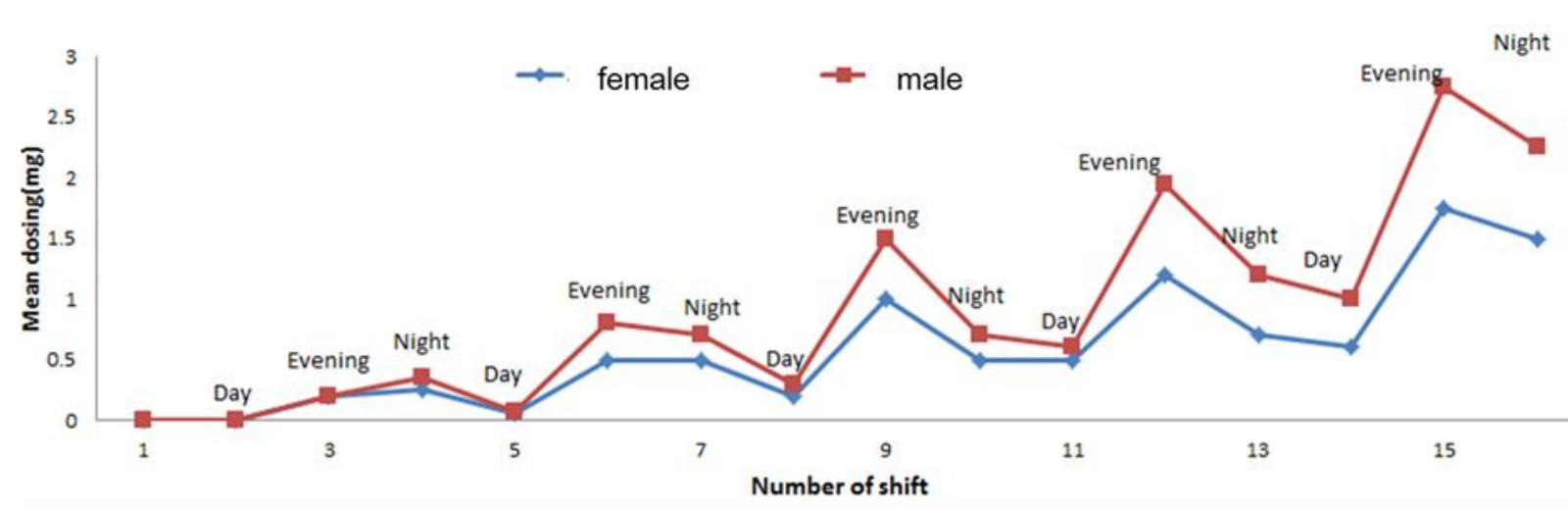

Figure 2 Mean doses of Benzodiazepine (lorazepam) by shift number

Table 2. Associations between evening shift and medication dosages

\begin{tabular}{|l|l|l|}
\hline Main results & $\begin{array}{l}\text { Relative Risk } \\
\text { First generation } \\
\text { antipsychotics (n=194) }\end{array}$ & Benzodiazepine $(\mathrm{n}=62)$ \\
\hline $\begin{array}{l}\text { Evening shift (4 PM- } \\
\text { midnight) }\end{array}$ & $1.67(1.13,2.89)^{\mathrm{c}}$ & $1.52(1.12,2.65) \mathrm{c}$ \\
\hline $\begin{array}{l}\text { Linear trend over } \\
\text { shifts }\end{array}$ & $1.38(1.32,1.49)^{\mathrm{c}}$ & $1.02(0.98,1.05)$ \\
\hline
\end{tabular}

a Each drug model included adjustment for age, ECOG, death in the palliative care unit, length of stay $<5$ days, sex, and weight

b Comparison of mean drug dose given on evening shift relative to mean doses on day and night shifts combined. c Statistical significance from $95 \%$ credible interval exclusive of zero.

\section{Discussion}

This study is the first one in which changes in patients' doses of psychoactive medications were quantitatively evaluated over time and diurnal variation. The results indicate that, regardless of a patient's sex, higher doses of first generation antipsychotics and benzodiazepine were given during the evening shift than during the day shift and the night shift. The mean dose of first generation antipsychotics and benzodiazepine increased over time and showed the least temporal variation according to nursing shifts. Also, men received higher doses of benzodiazepine, and first generation antipsychotics than did women. This difference is often attributed to men's higher body mass, more frequent perceptions that men's behavior is aggressive, and the need for greater sedation because of metabolic differences between men and women. However, after adjustments were made for covariates, including weight, men were still more likely than women to receive higher doses of first generation antipsychotics.

\section{Conclusions}

We found that palliative care center patients received increased doses of first generation antipsychotics and benzodiazepine during evening shifts. Whether patients and their family`s needs or factors related to the health care system are promoting the trends we observed is unclear, and further investigation into potential causes is needed. 